\title{
THE VALUE OF DYE DILUTION CURVES IN THE DIAGNOSIS OF INTRACARDIAC SHUNTS
}

\author{
BY \\ LEON RESNEKOV* \\ From the Cardiac Department, King's College Hospital \\ Received September 4, 1961
}

In an earlier paper (Resnekov, 1962), the effects of valvular incompetence on the nomal dye dilution curve were described. This paper deals with the effects of intracardiac shunts on the normal dye curve.

Broadbent et al. (1951) have shown that with a left-to-right shunt, the peak concentration is lower than would be expected for the amount of dye injected (Fig. 1), the disappearance slope is

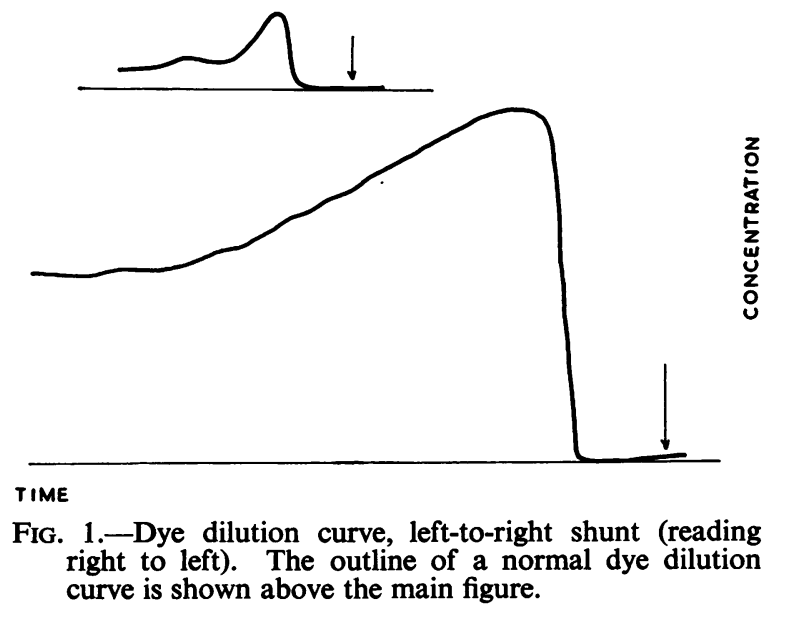

prolonged, and systemic recirculation of blood and dye causes an absence of the normal secondary peak of dye concentration. The appearance and build-up times are normal. The prolongation of the disappearance slope is only partly related to the cardiac output and cannot be used alone in the diagnosis of a left-to-right shunt. Broadbent and Wood (1954) have suggested that if the ratio of the disappearance to build-up time is calculated, the variation of the disappearance time with the cardiac output is no longer important and, further, the ratio will correlate with the volume of a leftto-right shunt as long as this is at least 35 per cent of the total pulmonary artery flow.

With a right-to-left shunt as shown by Swan, Zapata-Diaz, and Wood (1953), there is a shortened appearance time (Fig. 2), a hump on the build-up slope, and the peak concentration is less than would be expected for the amount of dye injected. The build-up slope is thus divided into two separate fractions, for blood and dye arrives at the sampling point via two routes-the right-toleft element completely by-passing the lungs to arrive first, and the remainder following closely in the normal way.

* Present address: The National Heart Hospital and Institute of Cardiology, London W.1. 


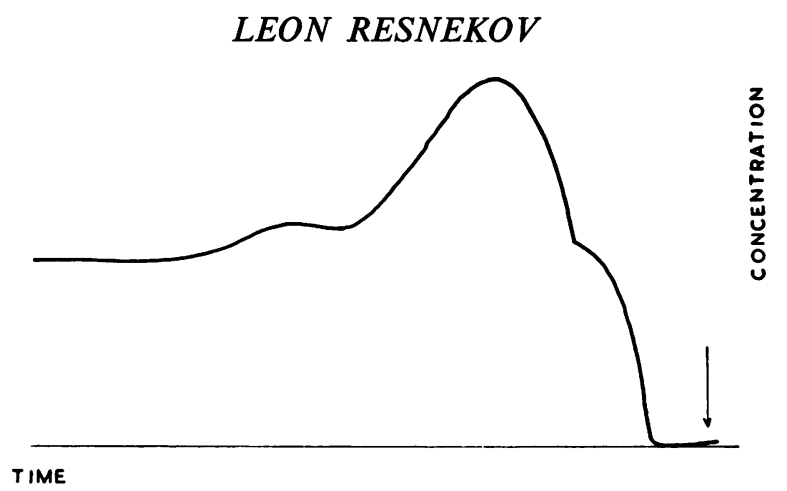

FIG. 2.-Dye dilution curve, right-to-left shunt (reading right to left).

Swan et al. (1953) consider that each component of the curve can be expressed as a right-angled triangle (Fig. 3), the two sides of which are the build-up time (BT) and maximal concentration (MC). The area of each triangle can be calculated, and hence the proportion of dye passing through the shunt will be given by

$$
\frac{\Delta^{\prime \prime}}{\Delta^{\prime}+\Delta^{\prime \prime}} \times 100
$$

where $\Delta^{\prime \prime}$ represents the right-to-left element that by-passes the lungs to arrive first at the sampling site, and $\Delta^{\prime}$ the volume of blood and dye that has passed normally through the pulmonary circulation and left side of the heart.

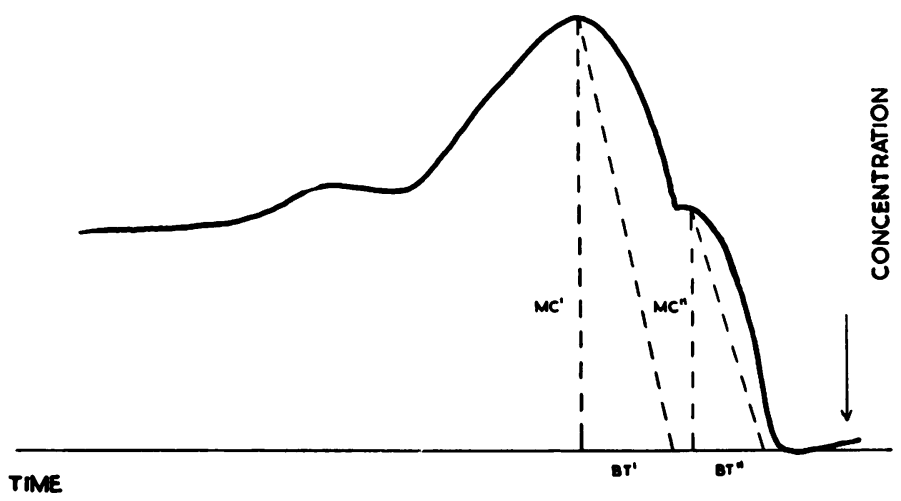

FIG. 3.-Quantitative use of dye dilution curves in right-to-left shunts (reading right to left). $\mathbf{B T}^{\prime}=$ Build up time of normal pathway. $\mathbf{M C}^{\prime}=$ Maximal concentration of normal pathway. $\mathrm{BT}^{\prime \prime}=$ Buildup time of dye by-passing lung. $\mathbf{M C}^{\prime \prime}=$ Maximal concentration of dye by-passing lung.

With a bidirectional shunt (Fig. 4), the appearance time is shortened. There is a hump on the build-up slope, the peak concentration is lower than would be expected for the amount of dye injected, and the disappearance slope is prolonged. There is also an absence of the normal secondary peak of dye concentration.

Dye dilution curves thus appear to be a simple and rapid means of diagnosing and localizing intracardiac shunts, and it is the purpose of this paper to assess the use of the method in actual practice.

\section{MATERIAL AND METHODS}

Seventy consecutive unselected patients with clinical evidence of intracardiac shunts underwent right heart catheterization. Pressure measurements were made with an inductance transducer and 


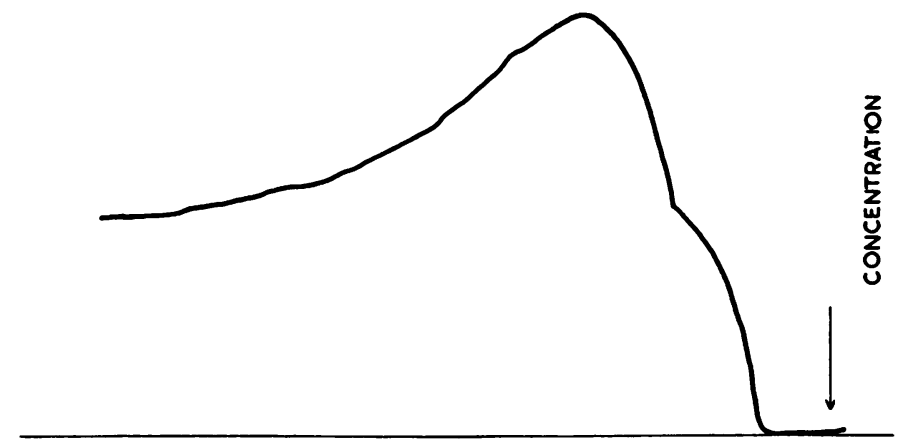

TIME

FIG. 4.-Dye dilution curve, bidirectional shunt (reading right to left.)

recorded photographically (New Electronic Products Limited). Oxygen saturations were measured by a Brinkman hæmoreflector and galvanometer (Kipp), and pulmonary and systemic flows were calculated by the Fick principle (Fick, 1870).

Dye curves were drawn using Coomassie blue (I.C.I.), $0 \cdot 5-1.0 \mathrm{mg} . / \mathrm{kg}$. body weight, injected into one or more chambers of the heart or into the great vessels via a cardiac catheter. An ear oximeter based on the design of Wood and Geraci (1949) was used, and the reduced output from its red cell was led to a chopper amplifier and pen recorder (Cambridge Instruments Limited). The sensitivity of the amplifier was such that curves of $8-10 \mathrm{~cm}$. peak concentration were obtained.

The cause and direction of the shunt in the 70 patients studied is listed in Table I.

TABLE I

Cause and Direction of Shunt in Patients Studied

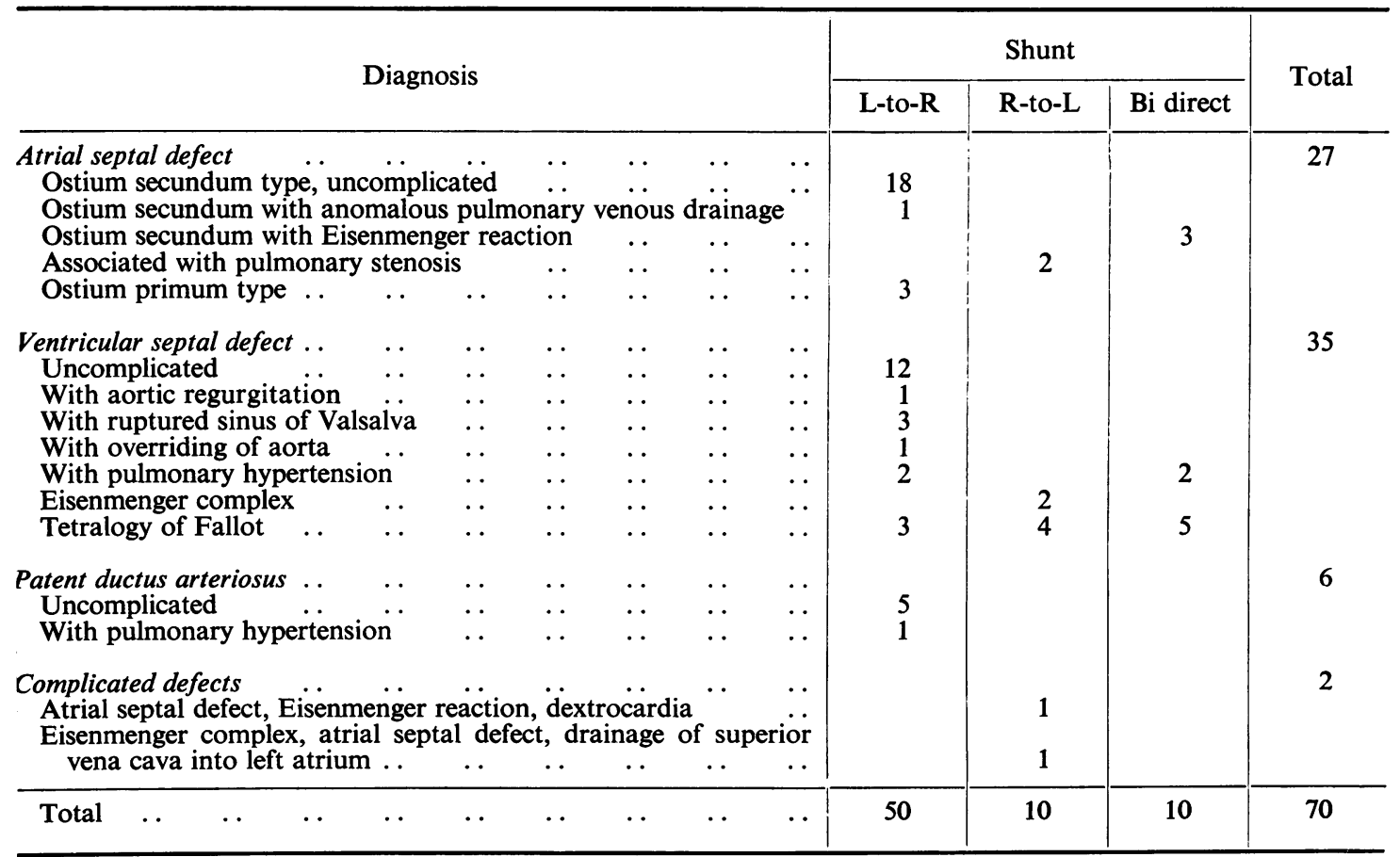




\section{RESULTS}

There was evidence clinically and at cardiac catheterization of a left-to-right shunt in 50 patients. Ten had a right-to-left shunt, and a bidirectional shunt was present in the remaining ten.

Of the left-to-right shunts 40 gave diagnostic dye dilution curves, but in the remaining 10 the curves were either normal or the abnormality was so slight that no conclusion could be reached. The relevant details of these 10 patients are set out in Table II.

TABLE II

Ten Patients with Left-to-Right Shunt and Inconclusive Dye Curves

\begin{tabular}{|c|c|c|c|c|c|c|}
\hline Patient No. & Diagnosis & DT:BT & $\begin{array}{c}\text { PF } \\
\text { (1./min.) }\end{array}$ & $\underset{(1 . / \mathrm{min} .)}{\mathrm{SF}}$ & $\mathbf{P}: \mathbf{S}$ & $\mathrm{Sh} / \mathrm{P} \%$ \\
\hline $\begin{array}{r}1 \\
2 \\
3 \\
4 \\
5 \\
6 \\
7 \\
8 \\
9 \\
10\end{array}$ & $\begin{array}{l}\text { ASD } \\
\text { ASD } \\
\text { VSD } \\
\text { VSD } \\
\text { VSD } \\
\text { VSD } \\
\text { VSD } \\
\text { VSD } \\
\text { PDA } \\
\text { PDA }\end{array}$ & $\begin{array}{l}4 \\
7 \cdot 9 \\
9 \cdot 6 \\
7 \cdot 4 \\
7 \\
9 \\
9 \cdot 7 \\
8 \cdot 5 \\
8 \cdot 5 \\
9 \cdot 5\end{array}$ & $\begin{array}{l}4 \cdot 8 \\
3.9 \\
7 \cdot 6 \\
6 \cdot 4 \\
4.9 \\
5 \cdot 1 \\
3 \cdot 6 \\
4.9 \\
6 \cdot 3 \\
6 \cdot 4\end{array}$ & $\begin{array}{l}3 \cdot 9 \\
3 \cdot 4 \\
5 \cdot 1 \\
4 \cdot 9 \\
4 \cdot 1 \\
3 \cdot 1 \\
2 \cdot 5 \\
3 \cdot 3 \\
4 \cdot 4 \\
4 \cdot 0\end{array}$ & $\begin{array}{l}1.2 \\
1.1 \\
1.5 \\
1.3 \\
1.2 \\
1.7 \\
1.4 \\
1.5 \\
1.4 \\
1.6\end{array}$ & $\begin{array}{l}18 \\
13 \\
30 \\
23 \\
16 \\
39 \\
30 \\
31 \\
30 \\
38\end{array}$ \\
\hline
\end{tabular}

BT = Build-up time. $\quad$ DT =Disappearance time. $\quad P F=$ Pulmonary flow. $S F=$ Systemic flow. $P: S=R a t i o$ of pulmonary to systemic flow. $\mathrm{Sh} / \mathrm{P} \%=$ Shunt as a percentage of the pulmonary flow.

In Fig. 5 a dye dilution curve is shown in a boy, aged 8 , with a patent ductus arteriosus. The curve is not diagnostic of a left-to-right shunt. At operation a ductus of $0.5 \mathrm{~cm}$. diameter was successfully ligated.

Right-to-left Shunt. In 2 out of the 10 cases the curves could not be interpreted owing to considerable oxygen swing which resulted in a very unstable base line.

Localization of a right-to-left shunt is one of the chief uses of dye dilution technique when applied to right heart catheterization. In 3 out of the 10 cases the level of the shunt as diagnosed by dye

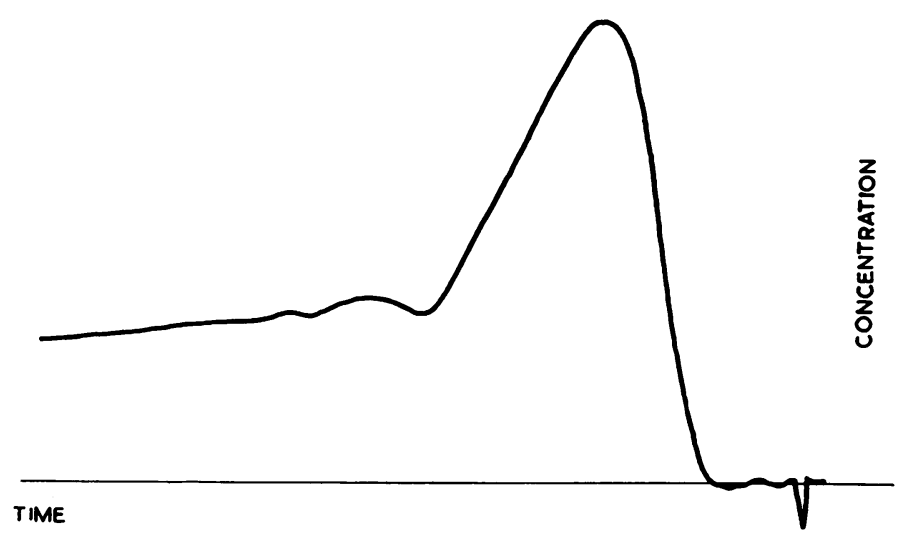

FIG. 5.-Dye dilution curve after $40 \mathrm{mg}$. Coomassie blue into right ventricle (reading right to left). Case of patent ductus arteriosus, subsequently ligated. Pulmonary flow 6.41 ./min., systemic flow 4.01 . $/ \mathrm{min}$. 
dilution curves was apparently shown to be at atrial level, but at operation all three were shown to have a ventricular septal defect. This point is illustrated in Fig. 6.

Bidirectional Shunt. All 10 cases gave diagnostic curves, and the site of the shunt was correctly placed in each.

\section{Discussion}

There is no doubt that dye dilution curves will provide very useful information in congenital heart disease. The technique has, however, certain limitations which must be stressed.

It is essential that a satisfactory recording device is used, and unless the high degree of amplification of the small output of the photoelectric cell is accompanied by a corresponding high degree of stability, the curve will be of little diagnostic value.

Coomassie blue has proved satisfactory as an indicator dilution substance. As long as the 2 per cent solution is used and the total dosage does not exceed $400 \mathrm{mg}$., toxic reactions should not occur. As already described (Resnekov, 1962) we have had only 3 toxic reactions in over 400 injections and in these three, a total of more than $500 \mathrm{mg}$. had been injected. Toxic reactions consist of nausea and vomiting, but a profound fall of systemic pressure may also occur; this happened in one of our patients. Staining of the skin does not occur with Coomassie blue. The short-lived blue colour that may be seen after injection is due to colouring of the plasma, and the dye is quickly excreted mainly in the bile (Taylor and Thorp, 1959).

Coomassie blue absorbs light maximally at $585 \mathrm{~m} \mu$, and consequently difficulty could be expected

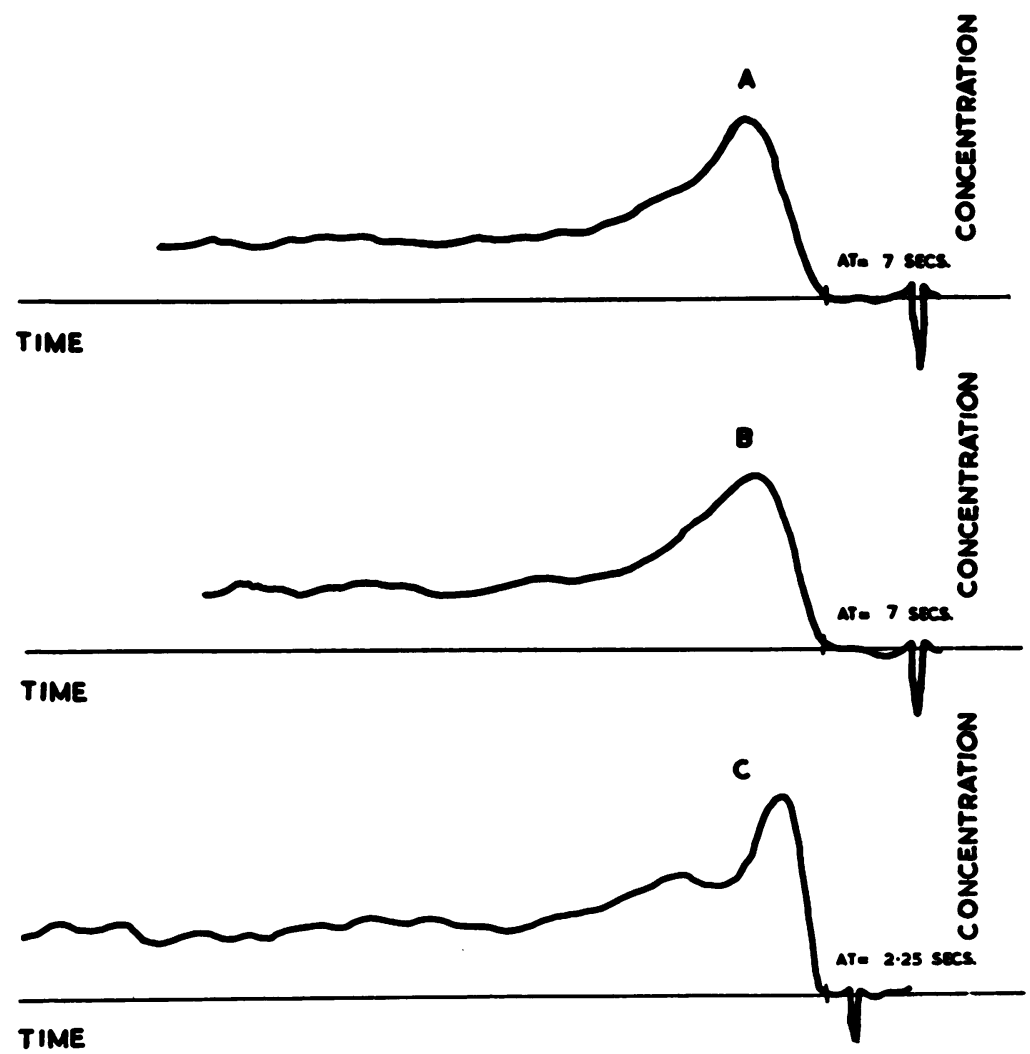

FIG. 6.-Dye dilution curves, tetralogy of Fallot, confirmed at operation (reading right to left). $A=60 \mathrm{mg}$. Coomassie blue into main pulmonary artery. $B=60 \mathrm{mg}$. Coomassie blue into right ventricle. $C=60 \mathrm{mg}$. Coomassie blue into right atrium. In curve $\mathrm{C}$ a large right-to-left shunt is shown at atrial level. 
in obtaining satisfactory curves in patients with considerable oxygen desaturation. In practice the dose of Coomassie blue may be increased, the sensitivity of the amplifier reduced, and a satisfactory curve obtained (Taylor and Shillingford, 1959). This is illustrated in Fig. 7.

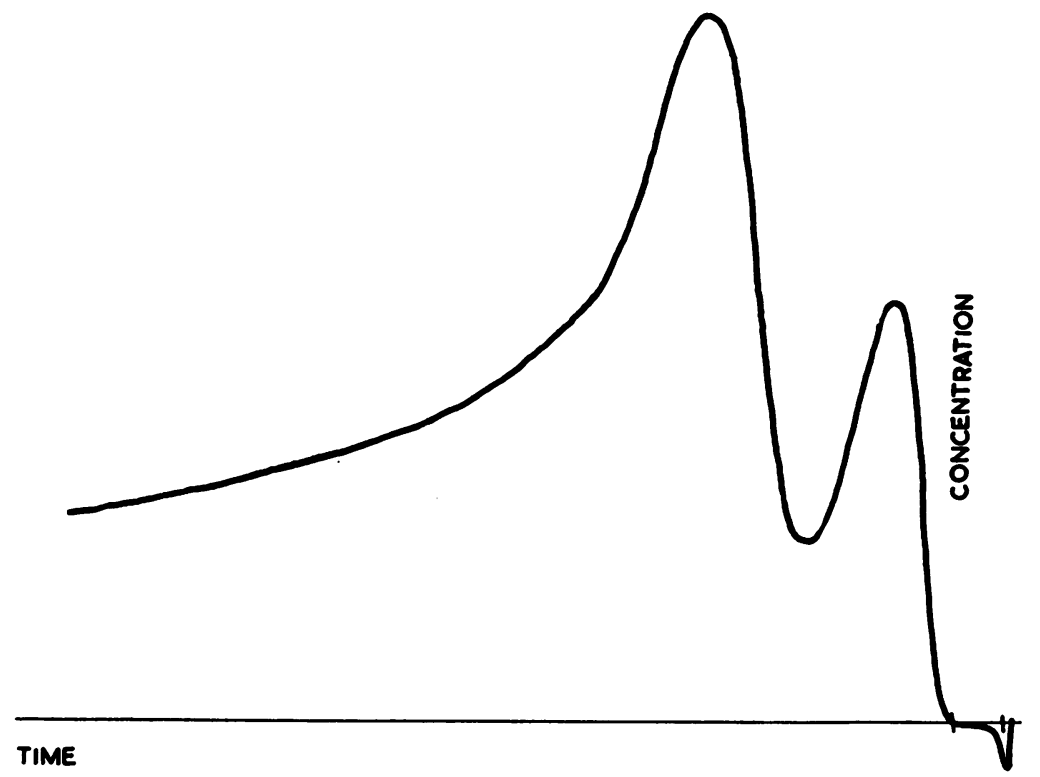

FIG. 7.-Dye dilution curve, $70 \mathrm{mg}$. Coomassie blue into right ventricle (reading right to left). Typical large right-to-left shunt. Arterial oxygen saturation, 79 per cent.

To overcome variations in reduced hæmoglobin interfering with light absorption of dyes in the red region of the spectrum, workers at the Mayo Clinic introduced indocyanine green (Fox et al., 1957) which has a peak light absorption at $800 \mathrm{~m} \mu$. This is the iso-electric point of the spectrum where oxyhæmoglobin and reduced hæmoglobin transmit light equally.

For the recording of dye curves using indocyanine green only the infra-red sensitive photocell is used; consequently the method is sensitive to changes in the optical density of blood that may be produced by variations in the rate of blood flow, additions of non-isotonic solutions, and variation in carbon dioxide tension (Fox and Wood, 1960). Furthermore the dye is not stable in aqueous solution and consequently has to be prepared just before injection. It is only poorly soluble in saline, but once dissolved in distilled water saline can be added to make the solution isotonic without risk of precipitation of the dye.

Our experience has been that dye dilution curves during right heart catheterization are of little help in the diagnosis of left-to-right shunts. A small left-to-right shunt may not be shown up on the curve. In general, unless the shunt is 40 per cent of the total pulmonary flow an equivocal curve may result. Nevertheless, in 4 out of the 50 left-to-right shunts, a diagnostic curve was obtained where the shunt was between 28 and 40 per cent of the total pulmonary flow.

The ratio of the disappearance to build-up time suggested by Broadbent and Wood (1954) in the diagnosis of left-to-right shunts is not of great practical value as it must surely depend on the volume of blood in the heart chambers quite apart from the presence or absence of a left-to-right shunt. On the other hand one can get a rough idea of the size of the shunt from the angle of the disappearance slope.

A point of practical importance is the comparative ease with which dye, when injected into a chamber of the right side of the heart where there is a septal defect, may be inadvertently propelled across the defect into the left side of the heart and so suggest a right-to-left shunt when none exists. 
This happened in two of our cases, both with an atrial septal defect. It is now our practice to inject dye into the venæ cavæ rather than the right atrium to avoid this.

It can thus be seen that dye dilution curves are less sensitive than oxygen saturation levels in diagnosing left-to-right shunts. Injecting dye into the right side of the heart will not localize the shunt. To overcome this Wood, Swan, and Helmholz (1957) have suggested injecting dye into a distal pulmonary artery while sampling the blood-dye mixture from different positions in the heart through a second catheter. This requires a whole blood cuvette.

We agree with Oakley et al. (1960) that right-to-left shunts may be shown up by dye dilution curves where arterial blood does not show any desaturation. As long as technically satisfactory curves can be obtained, even a very small shunt will show. Furthermore, selective injection of dye into the right side of the heart or pulmonary artery will localize the shunt.

Unless great care is taken to verify the position of the tip of the catheter before making the injectiun the level of the shunt will be wrongly placed. Even so, this happened in three of our cases. Our practice now is to make sure of the position of the catheter tip both by screening and by the recorded pulse wave from that site before and immediately after the injection. Another possible cause of incorrect localization of the shunt is dye leaking back to a proximal chamber through an incompetent valve.

We have found dye curves helpful in diagnosing abnormal pathways especially anomalous pulmonary venous drainage in association with atrial septal defect. This is illustrated in Fig. 8 where
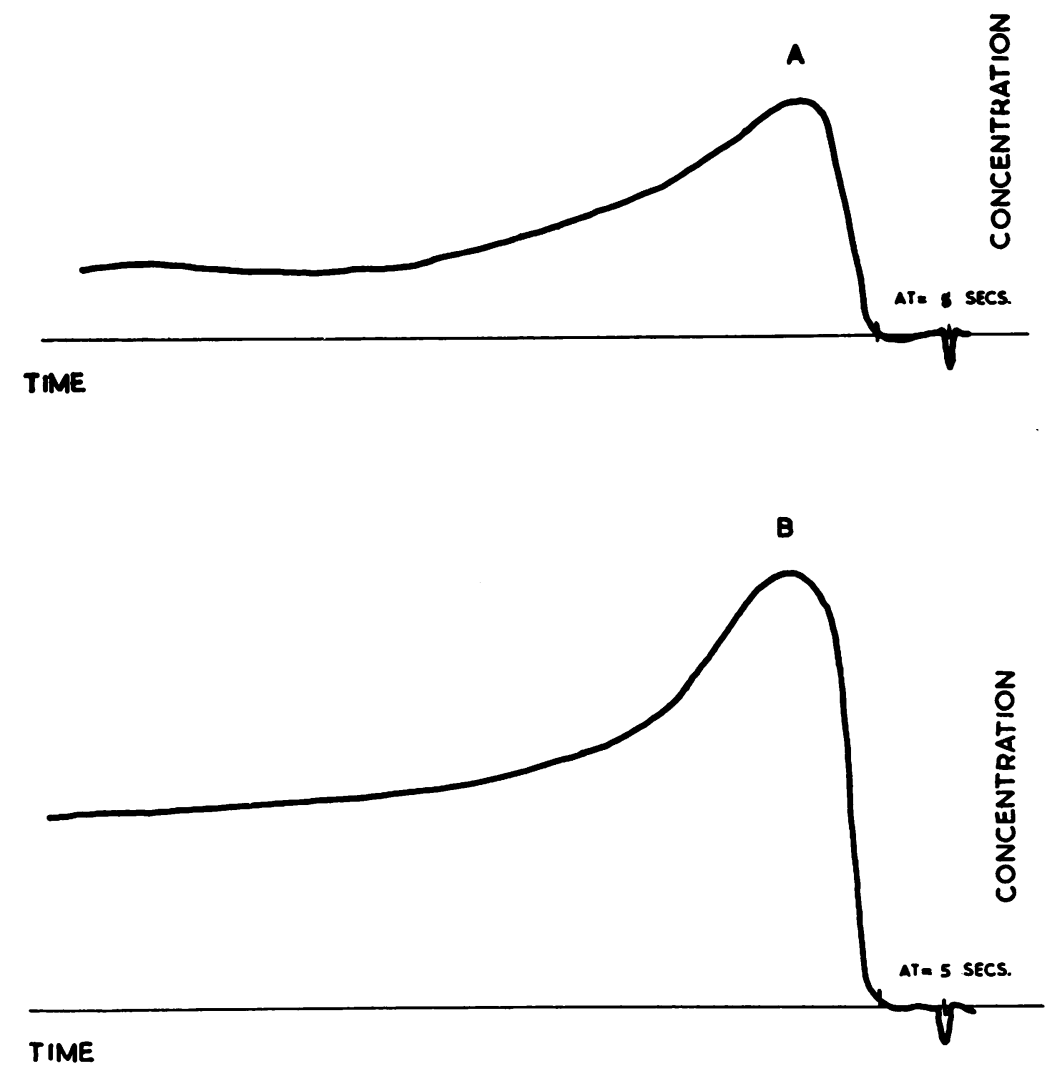

FIG. 8.-Dye dilution curves, anomalous pulmonary venous drainage (reading right to left). $A=40 \mathrm{mg}$. Coomassie blue into superior vena cava. $B=60 \mathrm{mg}$. Coomassie blue into anomalous pulmonary vein. In each case the drainage pathway is the right atrium. 
dye curves clearly show that the drainage pathway of blood from the anomalous pulmonary vein and superior vena cava is the same, namely via the right atrium.

We cannot agree with Falholt and Fabricius (1958) that dye dilution curves give disappointing results in congenital heart disease. We feel that it is a useful method of obtaining information that would not be readily available by right heart catheterization alone, but the limitations of the method must be fully realized, otherwise misleading information may be obtained.

\section{SUMMARY}

The results of dye dilution curves are presented in 70 patients with congenital heart disease with shunts, all of whom underwent right heart catheterization.

In 10 of the 50 left-to-right shunts, a diagnostic curve was not obtained, and a shunt of at least 40 per cent of the total pulmonary flow is usually required before the curve becomes diagnostic.

In 2 of the 10 examples of right-to-left shunt the curve was technically unreadable. Three other patients had their shunts incorrectly placed, and the reasons for this are discussed. shunt.

All 10 examples of bidirectional shunts gave satisfactory curves and accurate localization of the

The physical properties of Coomassie blue are compared with indocyanine green.

Limitations of the dye dilution technique are mentioned and their importance stressed.

My thanks are due to Dr. Samuel Oram for helpful criticism and advice in the preparation of this paper, and to Mr. W. P. Cleland for details of operative findings.

I would also like to express my thanks to Miss J. Goulding and her staff for technical help during cardiac catheterization and for help with the dye dilution curves.

\section{REFERENCES}

Broadbent, J. C., Clagett, O. T., Burchell, H. B., and Wood, E. H. (1951). Amer. J. Physiol., 167, 770.

, and Wood, E. H. (1954). Circulation, 9, 890.

Falholt, W., and Fabricius, J. (1958). Brit. Heart J., 20, 117.

Fick, A. (1870). S.-B. phys.-med. Ges. Würzb., p. 16.

Fox, I. J., Brooker, L. G. S., Heseltine, D. W., Essex, H. E., and Wood, E. H. (1957). Proc. Mayo. Clin., 32, 478.

, and Wood, E. H. (1960). Proc. Mayo Clin., 35, 732.

Oakley, C., Taylor, S., Wilcken, D., Hollman, A., Goodwin, J. F., and Shillingford, J. (1960). Brit. Heart J., 22, 533.

Resnekov, L. (1962). Brit. Heart J., 24, 17.

Swan, H. J. C., Zapata-Diaz, J., and Wood, E. H. (1953). Circulation, 8, 70.

Taylor, S. H., and Shillingford, J. P. (1959). Brit. Heart J., 21, 497.

Whorp, J. M. (1959). Brit. Heart J., 21, 492.

Wood, E. H., and Geraci, J. E. (1949). J. Lab. clin. Med., 34, 387.

—, Swan, H. J. C., and Helmholz, H. F., Jr. (1957). Proc. Mayo Clin., 32, 464. 